\title{
MACROMOLECULES IN THE BAYER PROCESS
}

\author{
Thelma J Whelan', Amanda Ellis', G. S. Kamali Kannangara ${ }^{2}$, \\ Craig P Marshall ${ }^{3}$, Damian Smeulders ${ }^{2}$ and Michael A Wilson ${ }^{2 *}$ \\ 'Department of Chemistry, Materials and Forensic Science University \\ of Technology, Sydney, Broadway 2007, ${ }^{2}$ Office of the Dean, \\ College of Science Technology and Environment, University of \\ Western Sydney, Locked Bag 1797, Penrith South DC, NSW 1797 \\ Australia, ${ }^{3}$ Australian Centre for Astrobiology, Department of Earth \\ and Planetary Sciences Macquarie University, Sydney NSW 2109 \\ Australia
}

\begin{abstract}
Organic matter enters the Bayer process during the formation of alumina from bauxite ore via dissolution in concentrated sodium hydroxide at high temperatures. This organic matter interferes with the crystallisation process in a number of ways. The nature of this organic matter is reviewed on the basis of molecular weight. While its function is not fully established, and the prevention of its role has yet to be achieved, much is known about its interaction. Two principle new discoveries have been made, namely 1) a host guest structure to the organic matter, and 2) that a variety of structures exist at different molecular weights. Rather than molecular weight fractions being simple polymers or alike macromolecules, they vary considerably in chemical structure from char to benzoic in nature. This means that organic matter exhibits an array of interactions modes during the crystallization of alumina.
\end{abstract}

Key words: Bauxite, alumina refining, macromolecules, humic material, sodium oxalate, poisoning

\footnotetext{
* To whom correspondence should be addressed
} 


\section{INTRODUCTION}

This review discusses recent advances in our knowledge of the role and structure of organic matter introduced with bauxite ore when producing alumina from that ore. Some details on the ore are first described, and then the type of organic matter present However, the main part of the review is concerned with the nature of the organic matter in the process and how it interferes with processing.

\subsection{Bauxite}

In weathered materials aluminium accumulates in clay minerals or in purely aluminous minerals such as, gibbsite, boehmite, and diaspore, which are the principal minerals of bauxite. Bauxite is a general term for a rock composed of hydrated aluminium oxides and is the material from which alumina is made. It was discovered 175 years ago by Pierre Berthier, a French mineralogist and is the only workable ore of aluminium (see review /1/)

The most popular model proposed for bauxite ore genesis is that bauxite is a residual sedimentary material formed by selective concentration of alumina after the dissolution of carbonate and silicate rocks in subtropical regions. High rainfall areas with pronounced dry seasors such as tropical monsoon and some Mediterranean climates produce saturation and drying of the surface, which results in intensive weathering. This intensive weathering leaches most of the minerals from the top few metres of the soil and leaves the insoluble components such as, iron and aluminium oxides, clay minerals and quartz. This weathering product is termed laterite. Bauxite is laterite enriched in aluminium and most deposits are of the post-Mesozoic age (225$70 \mathrm{Ma})$.

The amount of the various minerals in bauxite deposits depends on age. Young bauxite deposits are mostly gibbsite, and with age gibbsite gives way to boehmite and diaspore. Gibbsite occurs in monoclinic crystals in bauxites that are mostly of Tertiary (70 Ma) or younger age /I, 2/. Boehmite occurs in orthorhombic crystals in bauxites that are found in deposits of Tertiary and Upper Cretaceous (100-70 Ma) age /1, 2/. Diaspore occurs in orthorhombic crystals in bauxites of older deposits and metamorphic rocks formed by high pressure and elevated temperature $/ 1,2 /$. 
The mineralogical properties of bauxites largely determine the processing conditions for the recovery of alumina. Diaspore is the most difficult to process, and boehmite is more difficult to process than gibbsite. To be classified as economical to mine by today's technology, the bauxite grade must contain over $27 \%$ of aluminium oxides $/ 1 /$. In addition, the amount of inert material, iron oxides, titanium dioxide and non-reactive quartz determines the size of the separation circuits for the removal of this material (collectively termed red mud). These circuits can be very expensive and hence could have an impact on economic viability. Furthermore, the quantity of kaolinite and reactive silica largely determines whether bauxite is classified as commercial or not. At present, if bauxite contains more than $8 \%$ silica, it is classed as "not commercial" to process $/ 3 /$. One more important consideration in bauxite processing is the organic matter content. Significantly, Australian bauxite has the highest organic matter content in the world $(0.05-0.5 \% \mathrm{w} / \mathrm{w}) / 4 /$. The organic matter has numerous adverse effects on the process, which are discussed in this chapter.

\subsection{Bayer Process}

The Bayer process (/4/ and refs therein) is used for the industrial-scale production of alumina from the ore bauxite. A processing plant is essentially a three-stage device for heating and cooling bauxite in a large recirculating stream of a highly alkaline solution. In the first major stage, bauxite is added to 3.5-5 $\mathrm{M}$ sodium hydroxide at high temperatures $\left(145-245^{\circ} \mathrm{C}\right)$ in sealed vessels, termed digesters. The product liquor, which is supersaturated in sodium aluminate, is filtered to remove insoluble residues, such as oxides of silicon, iron and titanium and a geo-organic fraction, humin. This dark red filtrate is termed "red mud". Although the insoluble organics (humin) are removed in this fraction, alkali soluble organic degradation products remain in the process liquor and accumulate on recycling /5-7/.

For a Bayer process plant to operate cost-effectively, different temperatures and molarities of sodium hydroxide are used due to the variability of alumina found in bauxites (Equations 1-3). For gibbsite, $3.5 \mathrm{M}$ $\mathrm{NaOH}$, and temperatures of $135-150^{\circ} \mathrm{C}$ are used. Thus

$$
\gamma-\mathrm{Al}_{2} \mathrm{O}_{3} \cdot 3 \mathrm{H}_{2} \mathrm{O}+2 \mathrm{NaOH} \rightarrow 2 \mathrm{NaAl}(\mathrm{OH})_{4}
$$

For boehmite, $3.5 \mathrm{M} \mathrm{NaOH}$ and temperatures of $205-245^{\circ} \mathrm{C}$ are used. Hence 


$$
\gamma-\mathrm{Al}_{2} \mathrm{O}_{3} \cdot \mathrm{H}_{2} \mathrm{O}+2 \mathrm{NaOH}+2 \mathrm{H}_{2} \mathrm{O} \rightarrow 2 \mathrm{NaAl}(\mathrm{OH})_{4}
$$

and for diaspore, $5 \mathrm{M} \mathrm{NaOH}$, and higher temperatures are common. Hence

$$
\left.\alpha-\mathrm{Al}_{2} \mathrm{O}_{3} \cdot \mathrm{H}_{2} \mathrm{O}+2 \mathrm{NaOH}+2 \mathrm{H}_{2} \mathrm{O} \rightarrow 2 \mathrm{NaAl}(\mathrm{OH})_{4}\right)
$$

Some modern plants are being designed for the use of higher temperatures.

The next and most critical stage of the process involves cooling the product liquor to approximately $90^{\circ} \mathrm{C}$ and seeding it to precipitate aluminium hydroxide 'trihydrate'. This involves careful control of conditions to achieve high yields and a good quality product. It is at this point that soluble organic matter contributes detrimentally to the process through suppression of precipitation yields, incorporation of sodium ions, excessive liquor foaming, evolution of odours, increased liquor viscosity and density and effects on alumina crystallisation and agglomeration /5-7/.

After precipitation in the third and final stage, precipitated aluminium hydroxide is calcined at $1200^{\circ} \mathrm{C}$ to produce alumina $\left(\mathrm{Al}_{2} \mathrm{O}_{3}\right)$. Once again, the organics have an adverse effect on the process, causing dusting and decolourisation of the final product.

While a number of technologies have been considered for removing the organics such as photoxidation, prior fractionation of bauxite and post liquor burning, they are all expensive /4/ even though organics have been estimated to be responsible for as much as loss of $20 \%$ of production. Organic effects are on each of the processes described below. Methods of removal will be reviewed elsewhere.

\subsection{Crystallisation}

Crystallisation of alumina from a strongly alkaline solution involves the conversion of the aluminate ion $\left(\mathrm{AlO}_{4}\right)^{-}$which has tetrahedral geometry to octahedral alumina trihydrate $\mathrm{Al}_{2} \mathrm{O}_{3} \cdot 3 \mathrm{H}_{2} \mathrm{O}$. The process by which this occurs is poorly understood, although there have been suggestions that the aluminate ion dimerises and then addition occurs across the dimer to form a species with octahedral coordination /8/.

Nucleation. A greater understanding of the process can be gained by studying the formation of alumina species at lower $\mathrm{pH} / 9,10 /$. It is clear that species form polymers either in mildly acidic or mildly basic solution. These 
alumina species may be specific such as the $\mathrm{Al}_{13}$ species which consists of one tetrahedral aluminium surrounded by twelve octahedral species or long polymer chains, some of which are colloidal, i.e. nanoscale. Five-coordinated aluminium may also be formed transitorily /10/. It would seem logical therefore that nucleation occurs with a number of these species coordinating together so that dimensions of molecules are microsize rather than nanosize. Organic matter with strongly hydrogen bonding groups would coordinate to $\mathrm{Al}^{3+}$ species thereby interfering with the process.

Crystal Growth. A second source of interference is during the crystal growth. As the lattice forms, organic molecules may sit on the surface and need to be displaced for further aluminium species to precipitate. These organic molecules may occlude thereby creating lattice defects, or the displacement process may slow down the entire crystallisation. Further, these organic molecules may act as nuclei for other impurities or may prevent individual crystals agglomerating together. Thus some of the compounds present hamper the precipitation of aluminium hydroxide by adversely altering the desired product size distributions and by increasing the amounts of impurities in the product crystals. Organic matter can also affect the crystallisation of other materials in solution, such as sodium oxalate which needs to be removed.

The most important organic contaminant found in highest yield in Bayer liquors is sodium oxalate $/ 11$. At sufficiently high concentrations sodium oxalate may precipitate as fine needles onto which the aluminium hydroxide 'trihydrate' co-precipitates. Once the sodium oxalate obtains a high enough concentration, oxalate crystal nuclei form suddenly in the liquor resulting in what is termed "oxalate showers". These nuclei then allow for gibbsite nucleation onto the oxalate surface. This product is useless.

However the presence of some organic matter species in Bayer liquor are beneficial in this role (although detrimental in others) in that they may stabilise the sodium oxalate in solution, hence reducing the likelihood of the above process.

One might think that oxalate removal can be achieved just by calcination since oxalate can readily be decomposed by heat to carbon dioxide. In fact the sodium oxalate is decomposed to carbon dioxide; however the final alumina product is contaminated with high levels of sodium. This creates very small particles of alumina as the sodium reduces proper calcined particle agglomeration. Finely sized alumina $\left(<11 \mu \mathrm{m}^{2}\right)$ is not acceptable as a material for alumina production. 
In order to control the sodium oxalate concentration a side-stream process in which sodium oxalate is precipitated from the spent (unsaturated) liquor is used. The liquor and precipitate are vacuum filtered then passed through a fabric filter press. The resultant liquor now has a sodium oxalate concentration of approximately $2.0 \mathrm{~g} / \mathrm{L}$ compared with $4.0 \mathrm{~g} / \mathrm{L}$ prior to oxalate precipitation.

\section{BAUXITE ORGANIC MATTER}

\subsection{Bauxite Organic Matter Components}

The bauxite entering the process contains essentially two types of organic matter. The first type of organic matter is large vascular plant root systems that penetrate deep into the bauxite deposits from overlying trees. These systems contain largely lignin (up to $26 \% \mathrm{w} / \mathrm{w}$ ) and carbohydrates (up to $60 \% \mathrm{w} / \mathrm{w})$. The dissolution of these components under lower temperature Bayer process conditions has been reported /12,13/.

The second type of organic matter is geo-organic matter/humic material, which has accumulated over the history of the bauxite deposit through geochemical and bacterial transformation of plant and animal matter /11, 14/. This includes alkali soluble species that enter and impinge on the process, and any alkali insoluble organic material, humin, being removed with the red mud. These materials are not all plant derived, as many other alkanes and alkenes, polycondensed aromatics, high nitrogen and long chain fatty acids /11-17/, can originate from bacteria, and fungi. The presence of charcoal-like material termed "char" from ancient forest fires has also been observed in soils and humic extracts $/ 15,16,17 /$ and bauxite /18/. Tests carried out on one of the "char" samples suggest that it is largely insoluble and is expected to be removed along with red mud $/ 18 /$.

Given the significance of organic matter content to the process, industrial confidentiality restricts reports in the open literature on organic matter distribution in individual bauxite deposits. However there is at least one report on the organic matter in bauxite and this shows it is not unlike that in many soils $/ 19 /$.

\subsection{Host guest theory}

It is clear that a myriad of chemical compounds of different molecular weights make up the organic matter in soils and would therefore end up in 
bauxite. For organic matter produced in reducing environments, such as coal and lignite, a Host Guest theory has been proposed based on solubility and reactivity $/ 20,21 /{ }^{1} \mathrm{H}$ NMR spectral data also revealed the existence of two groups of molecules in bituminous coals with different molecular rigidities, i.e. rigid large hosts and smaller mobile guests, although there will be rapidly moving groups in hosts such as methyl groups which blur the distinction.

It is also probable that these assemblies could exist in soils and in bauxite /22/. Despite attempts to remove low molecular weight organic matter by dialysis, specific molecular weight fractions revealed the presence of low molecular weight organic matter $/ 22 /$. These host-guest interactions may occur in a variety of humic macromolecular compounds in the environment. The exact mechanism of entrapment is not known but it is likely that the organic guest molecules are included in the host molecule via formation of intermolecular interactions such as hydrogen bonding. Physical entrapment in the large host structure is also possible.

Another method could be through chelation to metal ions. This may be a mechanism of breaking intra or intermolecular interactions, which may create voids or indeed a mechanism of forming other voids. Chelation may release guests or entrap others. Energetically the destruction of host-guest complexes is expected to be less demanding than the destruction of covalent bonds. Indeed it has been demonstrated that humic substances under go facile degradation with UV radiation rather than polymerisation /23-26/. It can be envisioned that a series of events are taking place, for example, oxidation of host component phenols to quinones which removes any possibility of hydrogen bonding and then subsequent release of small molecular weight guests.

\subsection{Dissolution of Lignin}

In elucidating the role of different organic components in wood and roots it is desirable to separate lignin /27/ from carbohydrate. Klasons lignins Callitris rhomboidea (gymnosperm), Corymbia callophylla (angiosperm) and Eucalyptus marginata (angiosperm) roots have been digested under Bayer laboratory simulated conditions at $145^{\circ} \mathrm{C} / 12,13 /$.

The dissolution of lignin under highly alkaline conditions is far from trivial. The degree of dissolution is dependent upon the plant species, i.e. gymnosperm or angiosperm. Plant material high in syringyl (angiospermous) monomers (3,5-dimethoxy, 4-ether aryl compounds) in the lignin show an 
increase in dissolution in comparison to plants high in guaiacyl (gymnospermous) monomers (3-methoxy, 4- ether aryl compounds). In addition, a variety of linkages, which tether the monomers, make lignin dissolution highly complex. The fact that the kinetics are not single order in lignin and need to be expressed effectively by a series of exponentials suggests that more than one bond is broken during dissolution and that these occur at different rates. It also suggests that either the concentrations of these bonds and /or types of bonds vary in different lignins. This result is important as it means that different plants will behave differently in the Bayer process.

The breakage of $\beta-O-4$ linkages is believed to be the rate-determining step for dissolution of lignin in alkali and is initiated through base attack and removal of protons on the oxygen at the $\alpha$ carbon followed by intramolecular nucleophilic displacement of phenolic anions /28/. The polymeric and crosslinked nature of lignin induces physical constraints that make it less reactive toward attacking species after the initial removal of the $\beta-O-4$ linkages.

Solid state ${ }^{13} \mathrm{C}$ NMR analysis shows, after correction for relaxation, the amounts of various structural carbon groups in the extracts and residues. This is not particularly useful, except for showing trends in dissolution. However, by combining yield data it is possible to determine changes in structural group content as the original lignin dissolves. The total amount of carbon in a functional group $\left(\Sigma f_{C}\right)$ in solid and solution phase is given in $g / 100 \mathrm{~g}$ of original lignin (Equation 4). This data is given in Table 1 for one example.

$$
\begin{aligned}
& \Sigma \mathrm{f}_{\mathrm{C}}=\left[\left(\% \mathrm{C}_{\text {residue }} \mathrm{f}_{\mathrm{C} \text { residue } \% \text { yield }} \text { residue }\right) / 100\right]+ \\
& {\left[\left(\% \mathrm{C}_{\text {extract }} \mathrm{f}_{\mathrm{C} \text { extract }} \% \text { yield } \mathrm{extract}_{\mathrm{e}}\right) / 100\right]}
\end{aligned}
$$

In equation (4), the $\% \mathrm{C}_{\text {residue }}$ and $\% \mathrm{C}_{\text {extract }}$ are the percentage carbon in each Klason lignin, in the residue or extract respectively. The parameter $f_{C}$ is the fraction of a particular carbon type in the residue or extract from integration of relaxation corrected solid-state NMR spectra and $\%$ yield ${ }_{\text {residue }}$ and $\%$ yield $_{\text {extract }}$ are the yields of the residue or recovered extract, respectively.

For Callitris rhomboidea there appears to be an initial reaction that involves loss of $22 \%$ carbon as aromatic and methoxy carbon (Table 1). Aromatic carbon drops by $53 \%$ of the original aromatic carbon. Some aromatic carbon must be converted by base to gas, carbonate or carbon dioxide or other small volatile molecules lost during work up. There is however an increase in aliphatic carbon. Hydroxylation of syringyl and 
related compounds, followed by ring opening with carbon capture, probably occurs by intramolecularly capturing hydrogen that is generated in any base catalysed organic matter oxidation reaction (schematically for a carboxylic salt, $\mathrm{RCH}_{3}+\mathrm{H}_{2} \mathrm{O}+\mathrm{NaOH} \rightarrow 6 \mathrm{H}^{\prime}+\mathrm{RCOONa}$ ). Table 1 shows that only a small amount (5\% total) of further gasification occurs for Callitris rhomboidea with increasing time. The same initial processes appear to be occurring for Corymbia calophylla. and Eucalyptus marginata. For these two lignins $11-12 \%$ of the carbon is volatilised. The trend in initial loss of aromatic carbon is Callitris rhomboidea $>$ Eucalyptus marginata $>$ Corymbia calophylla. For Corymbia calophylla there is virtually no initial loss.

These results are confirmed by the change in methoxy content. There is an initial rapid loss for Callitris rhomboidea due to aryl ring opening. After initial dissolution for all three lignins this continues but at a much slower rate, if at all, and aromatic ring decomposition stops. Indeed some aromatic carbon is recovered through later aromatisation reactions.

The most interesting feature of Table 1 is the reduction in alkoxy carbon. Callitris rhomboidea, the gymnosperm, which has the lowest apparent content (6.4\%), has a value of only $2.0 \%$ after $96 \mathrm{hr}$. Eucalyptus marginata has $9.7 \%$ carbon of this type but shows a loss to $4.3 \%$ and a faster rate of dissolution. On the other hand Corymbia calophylla has $13.0 \%$ O-alkyl carbon and this reduces to $6.3 \%$. Most of this loss is during the initial dissolution, and for Corymbia calophylla, O-alkyl cleavage is almost over after initial reaction but for the other lignins the reaction continues at a slower rate. Although the results show that the rate of dissolution is clearly dependent on the syringyl content, the electron donating ability of a second methoxy group on the aryl ring should however increase the energy of the $\beta$ O-4 decomposing transition state through the 4 position, slowing the rate. However it is the gymnosperm that dissolves slowest, not the angiosperms. One possible explanation is that because a di-aryl linkage can replace the methoxy group in gymnosperms, this holds the lignin together, preventing dissolution. However it is difficult to see how hydroxide slowly breaks this linkage and it appears dissolution requires the $\beta-O-4$ linkage to hydrolyse. Perhaps, in the early dissolution for gymnosperms there are internal rearrangements of structures with $\beta-O-4$ to $\alpha-O-4$ linkages which then hydrolyse slower. Such reactions have been suggested for other lignin reactions and demonstrated for model lignin dimer hydrolysis $/ 27,28 /$.

The degradation products from the lignin monomers are aromatic carboxylic acids, but their side chains and ring opened products are 


\begin{tabular}{|c|c|c|c|c|c|c|c|c|}
\hline & & $\omega$ & $\begin{array}{ll}\infty & \infty \\
\infty & \eta \\
n & \eta\end{array}$ & $\left|\begin{array}{l}\infty \\
\infty \\
\infty \\
q\end{array}\right|$ & $\begin{array}{l}\infty \\
\dot{v}\end{array}$ & $\begin{array}{l}\dot{v} \\
\dot{v}\end{array}$ & $\ddot{v}$ & \\
\hline & & 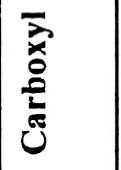 & $\underset{\sim}{\infty} \stackrel{-i}{\sim}$ & $\grave{0}$ & $\Xi$ & $\begin{array}{c}\infty \\
0\end{array}$ & $\Xi$ & $\stackrel{0}{-}$ \\
\hline 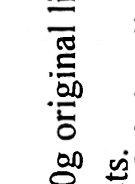 & $\vec{z}$ & 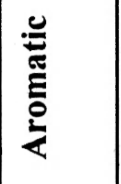 & 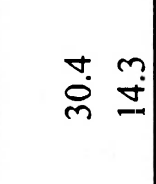 & $\begin{array}{l}0 \\
\infty \\
\infty\end{array}$ & 00 & $\stackrel{0}{\infty}$ & $\begin{array}{l}\infty \\
\mathbb{N}\end{array}$ & $\frac{N}{N}$ \\
\hline 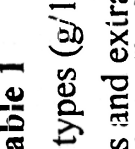 & 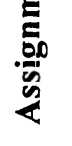 & گ્ર & $\begin{array}{cc}\nabla & n \\
0 & 0\end{array}$ & gे & ֶָ. & $\stackrel{n}{n}$ & $\bar{i}$ & $\stackrel{\circ}{\sim}$ \\
\hline 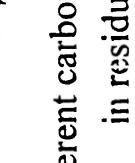 & & 胥 & $\vec{\forall} \stackrel{\infty}{\sim}$ & $\stackrel{\nabla}{\dot{m}}$ & $m$ & $n$ & $\stackrel{\infty}{\sim}$ & $\vec{i}$ \\
\hline $\begin{array}{l}\frac{0}{0} \\
\frac{0}{0}\end{array}$ & & 存 & $\bar{v} \stackrel{0}{\sim}$ & 옴 & 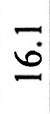 & ก̋' & $\stackrel{0}{\check{I}}$ & $\begin{array}{l}\ddot{v} \\
\ddot{q}\end{array}$ \\
\hline & & 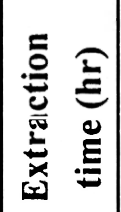 & 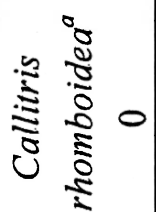 & - & $n$ & $\mathbb{N}$ & in & $\stackrel{2}{\circ}$ \\
\hline
\end{tabular}




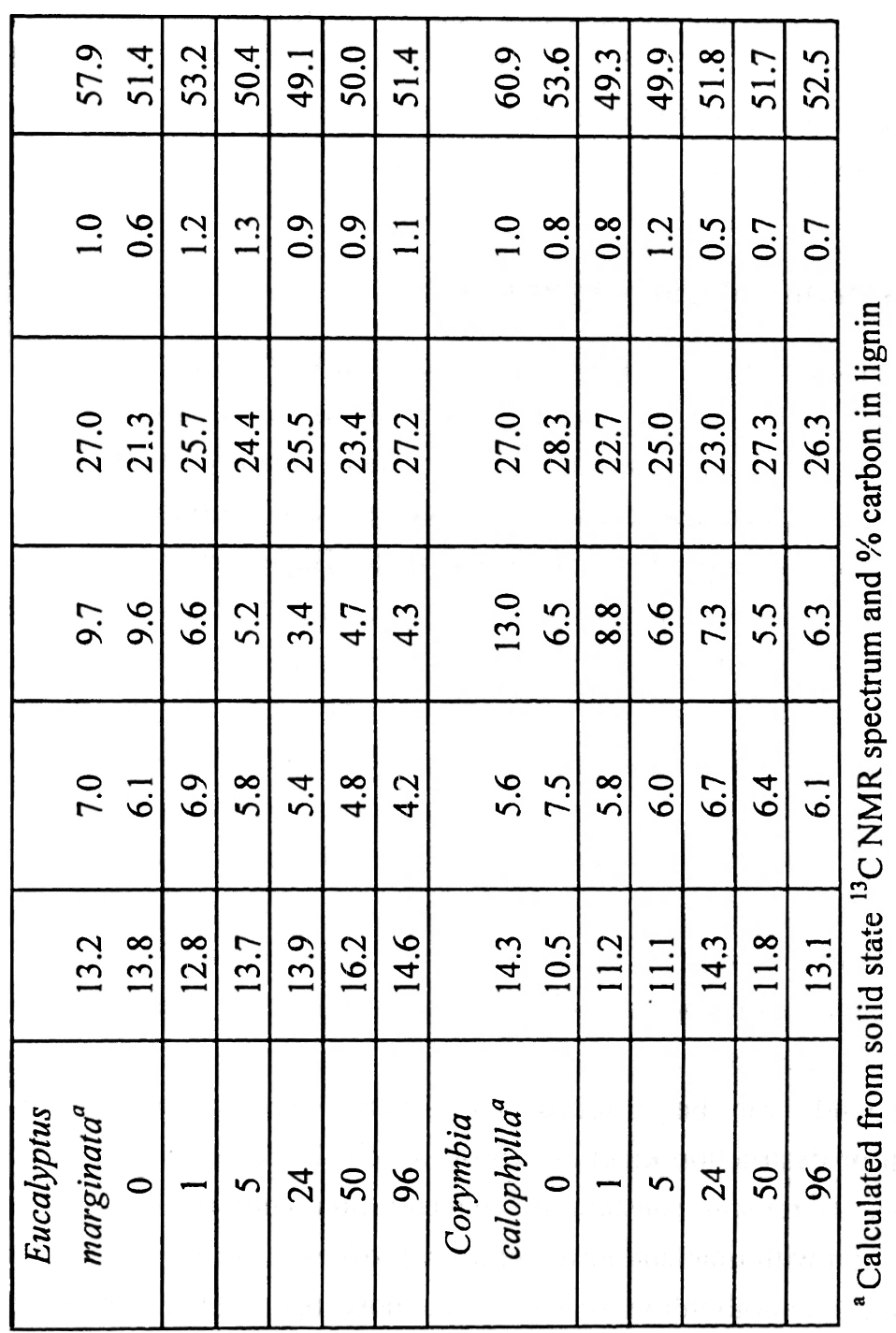


polyalcohol and polyhydroxy structures. These are known poisons and can interfere with precipitation of both alumina and the by-product sodium oxalate. Formation of aliphatic chain structures under the conditions described could oxidise to alcoholic species, which are undesirable. However, it does seem that the conditions are harsh enough to make minimal impact arising from the lignin component of plant tissue. The results show that the degree of $\beta-O-4$ linkages and hence the production of these phenols is plant specific, indeed Klason lignin type specific. Hence any technology that can remove specific plants may be of value.

\subsection{Dissolution of Carbohydrates}

Carbohydrates are a significant organic input into the process, whether in native plant matter or as bacterial by-products. Cellulose, in particular, decomposes to give glucose units which readily undergo further decomposition processes, even under less severe conditions. Typically the major decomposition products of glucose under Bayer process conditions are sodium formate, sodium acetate and sodium lactate $/ 29,30 /$.

Isolation of water-soluble native plant carbohydrates that might enter the Bayer process has been achieved /13/ and their dissolution studied. Gas chromatography-mass spectrometry (GC/MS) chromatographs of the tetramethylsilane (TMS) derivatives of these digestion extracts were useful in determining what species are being formed under dissolution. Each carbohydrate extract digestion yielded a wide variety of compounds, the majority of which were mono-, di- and tri- carboxylic and hydroxy aliphatic and aromatic carboxylic acids of low molecular weight and some carbohydrate species.

Compounds can be grouped into several classes according to their formation or destruction kinetics. Those which: 1) decrease in concentration with time, 2) remain constant in concentration with time, 3) increase in concentration with time and have complex profiles. Carbohydrates such as Dxylose (a), $\beta$-D-arabofuranose (b), D-mannose (c), $\alpha$-D-arabopyranose (d), D-lyxose (e), xylitol (f), D-ribose (g), D-glucose (h), D- altrose (i), D-allose (k), and $\beta$-D-fructofuranosyl- $\alpha$-D-glucopyranoside (l), shown in Figure 1, were found to decrease in concentration for all three plant digestions. Furans such as 2-furancarboxylic acid also decrease in concentration. It is well known that furans are derived from thermal decomposition of carbohydrates. Hence they are an intermediate that is rapidly decomposed. However, it is 
significant that the carbohydrate glucitol (j) remains almost constant in concentration for all three-plant digestions. This carbohydrate species is characteristic of many virulent precipitate poisons.

Almost all the small substituted aliphatic carboxylic acids increase in concentration. Lactic acid, hydroxyacetic acid, 2-hydroxybutanoic acid, propanedioic acid, 4-hydroxybutanoic acid and 2-hydroxypropanedioic acid are such examples. This is also true of oxalic acid.

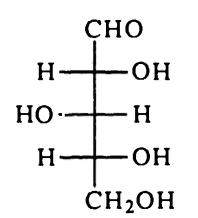

(a)

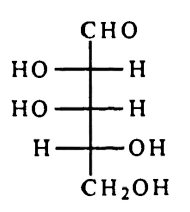

(e)

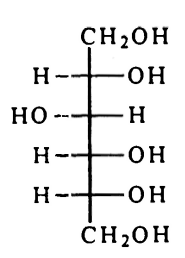

(j)

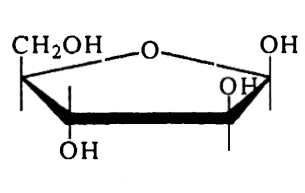

(b)

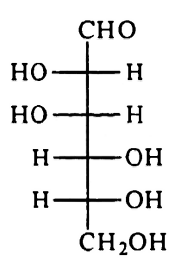

(c)

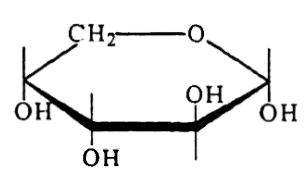

(d)

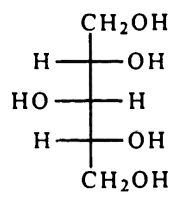

(f)

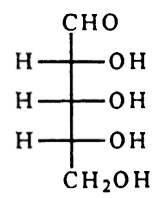

(g)

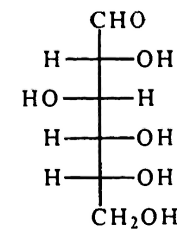

(h)

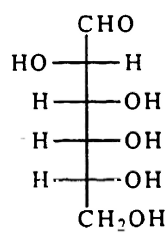

(i)

Fig. 1 Structures of carbohydrates such $D$-xylose (a), $\beta$-D-arabofuranose (b), D-mannose (c), $\alpha$-D-arabopyranose (d), D-lyxose (e), xylitol (f), D-ribose (g), D-glucose (h), D- altrose (i), D-allose (k), and $\beta$-Dfructofuranosyl- $\alpha$-D-glucopyranoside (l). 
As noted in section 2.3, the compounds formed from lignin during Bayer processing are different from many of the compounds shown here. Hence it is clear that selective removal of carbohydrates before Bayer processing will influence the nature of organics present in the Bayer liquor and this may affect yields. Water washing is obviously a potential methodology but drying costs could be prohibitive. Another option is thermal maturation.

Like lignins, the mechanism by which carbohydrates yield small molecular weight compounds is by no means trivial, but it is clear from previous work that acetate, formate and lactate are derived from glucose during Bayer processing $129,30 \%$. The formation of such species is best illustrated by labelling studies, which can indicate where carbons on different parts of the carbohydrate molecule end up. Digestions of unlabeled and labeled $1-{ }^{13} \mathrm{C}$-D-glucose and $6-{ }^{13} \mathrm{C}-\mathrm{D}$-glucose for $1 \mathrm{hr}$ at $145^{\circ} \mathrm{C}$ in $3.5 \mathrm{M}$ $\mathrm{NaOH}$ have been carried out $/ 30 /$. Table 2 shows enhanced yields of ${ }^{13} \mathrm{C}$ in 'products relative to that in the original unlabeled mixture of products.

It is clear that these values are greater than one, and that the label from 1${ }^{13} \mathrm{C}$-D-glucose and $6-{ }^{13} \mathrm{C}$-D-glucose ends up in all carbons in the products. It is also shown in Table 2 that the labeled lactate is the predominant compound formed from both $1-{ }^{13} \mathrm{C}$-D-glucose and $6-{ }^{13} \mathrm{C}$-D-glucose under these conditions. The labelling occurs at all three lactate carbons but in different proportions and shows that from $1-{ }^{13} \mathrm{C}$-D-glucose the production of $\mathrm{CI}$ and C3 labeled lactate is favoured while from $6-{ }^{13} \mathrm{C}$-D-glucose the production of C3 labeled lactate only is more favoured. The distribution of label in other compounds is also very dependent on the position of label in glucose. In formate the amount of label also depends on the source used. In acetate more label occurs on methyl carbon from $1-{ }^{13} \mathrm{C}$ labeled than $6-{ }^{13} \mathrm{C}$ labeled carbon.

unce formed, the label then becomes indiscriminately scrambled as lactate decomposes. $1-{ }^{13} \mathrm{C}$-sodium-L-lactate studies showed that ${ }^{13} \mathrm{C}$ labeled carboxylate $\left(\mathrm{COO}^{-}\right)$is scrambled equally among carbonate and both carbons in product ethanol molecules. This suggests a common 1,2,3 trihydroxycylopropane intermediate. However, decomposition of lactate can be influenced by a number of factors $/ 29 /$. Agents that inhibit hydride, hydroxy or methyl transfer may be effective since the stability of transition states to the species shown will be sensitive to a number of reaction conditions. 
Table 2

${ }^{13} \mathrm{C}$ distribution (\%) and enhanced yield in products from unlabeled digested $\alpha-D-(+)$-glucose and labeled $1-{ }^{13} \mathrm{C}$-D-glucose and $6-{ }^{13} \mathrm{C}$-D-glucose digestions in $3.5 \mathrm{M} \mathrm{NaOH}$ for $1 \mathrm{hr}$ at $145^{\circ} \mathrm{C}$.

\begin{tabular}{|c|c|c|c|c|c|c|}
\hline Product & $\begin{array}{c}\text { Chemical } \\
\text { shift } \delta \\
(\mathrm{ppm})\end{array}$ & \begin{tabular}{|c|} 
Unlabeled $\alpha-$ \\
D-(+)-glucose \\
digestion \\
$(1 \mathrm{hr})$
\end{tabular} & \begin{tabular}{|c|}
$1-{ }^{13} \mathrm{C}-\mathrm{D}-$ \\
glucose \\
digestion (1 \\
$\mathrm{hr})$
\end{tabular} & $\begin{array}{l}\text { 6- }{ }^{13} \mathrm{C}-\mathrm{D}- \\
\text { glucose } \\
\text { digestion } \\
(1 \mathrm{hr})\end{array}$ & $\begin{array}{c}\text { Enhanced } \\
\text { yield }^{\mathrm{n}} \\
1-{ }^{13} \mathrm{C}-\mathrm{D}- \\
\text { glucose } \\
\text { digestion } \\
(1 \mathrm{hr}) \\
\end{array}$ & $\begin{array}{c}\text { Enhanced } \\
\text { yield" } \\
6-{ }^{13} \mathrm{C}-\mathrm{D}- \\
\text { glucose } \\
\text { digestion } \\
(1 \mathrm{hr}) \\
\end{array}$ \\
\hline $\begin{array}{l}\quad \text { Lactate } \\
\mathrm{COO}^{-} \\
\left.\right|_{\mathrm{CHOH}} \\
\left.\right|_{\mathrm{CH}_{3}}\end{array}$ & $\left.\right|_{23.2} ^{185.6}$ & $\begin{array}{l}\left.\right|^{28.7} \\
24.8 \\
21.6\end{array}$ & $\begin{array}{l}49.5 \\
\left.\right|_{37.8} ^{1.0}\end{array}$ & $\begin{array}{l}\left.\right|_{33.7} ^{24.2} \\
1.1\end{array}$ & $\begin{array}{l}155.2 \\
3.7 \\
157.9\end{array}$ & $\begin{array}{l}\left.\right|_{140.5} ^{76.2} \\
3.7\end{array}$ \\
\hline $\begin{array}{l}\text { Glycolate } \\
\mathrm{COO} \\
1 \\
\mathrm{CH}_{2} \mathrm{OH}\end{array}$ & $\left.\right|_{66.5} ^{184.6}$ & $\left.\right|_{2.8} ^{2.7}$ & $\begin{array}{l}3.5 \\
0.1 \\
\end{array}$ & $\begin{array}{l}2.9 \\
31.7 \\
\end{array}$ & $\begin{array}{l}116.6 \\
3.7 \\
\end{array}$ & $\begin{array}{l}96.4 \\
1019.2\end{array}$ \\
\hline $\begin{array}{l}\quad \text { Acetate } \\
\mathrm{COO}^{-} \\
\mathrm{CH}_{3}\end{array}$ & $\left.\right|_{26.3} ^{184.1}$ & $\begin{array}{l}0.1 \\
0.1\end{array}$ & $\left.\right|_{1.3} ^{0.1}$ & $\begin{array}{l}0.1 \\
0.4\end{array}$ & $\begin{array}{l}90.0 \\
1169.8\end{array}$ & $\begin{array}{l}\left.\right|_{359.9} ^{90.0} \\
\text {. }\end{array}$ \\
\hline
\end{tabular}


Table 2 (continued)

${ }^{13} \mathrm{C}$ distribution (\%) and enhanced yield in products from unlabeled digested $\alpha-\mathrm{D}-(+)$-glucose and labeled $1-{ }^{13} \mathrm{C}$-D-glucose and $6-{ }^{13} \mathrm{C}$-D-glucose digestions in $3.5 \mathrm{M} \mathrm{NaOH}$ for $1 \mathrm{hr}$ at $145^{\circ} \mathrm{C}$.

\begin{tabular}{|c|c|c|c|c|c|c|}
\hline $\begin{array}{l}\quad \text { Ethanol } \\
\mathrm{CH}_{2} \mathrm{OH} \\
\mathrm{CH}_{3}\end{array}$ & $\begin{array}{l}57.0 \\
17.6\end{array}$ & $\begin{array}{l}3.0 \\
3.2\end{array}$ & $\begin{array}{l}0.1 \\
0.3\end{array}$ & $\begin{array}{l}0.1^{b} \\
\mid \\
0.1\end{array}$ & $\begin{array}{l}2.8 \\
8.3 \\
\end{array}$ & $\begin{array}{l}2.8 \\
2.8 \\
\end{array}$ \\
\hline $\begin{array}{l}\text { Formate } \\
\mathrm{HCOO}^{-}\end{array}$ & 173.8 & 0.1 & 1.3 & 0.5 & 1169.8 & 449.9 \\
\hline $\begin{array}{l}\text { Carbonate } \\
\mathrm{CO}_{3}{ }^{2-}\end{array}$ & 170.9 & 9.7 & 0.4 & 0.4 & 3.7 & 3.7 \\
\hline $\begin{array}{l}\text { Other } \\
\text { products }\end{array}$ & & 3.2 & 4.6 & 4.8 & 129.5 & 135.0 \\
\hline
\end{tabular}

${ }^{\text {a }}$ Enhanced yield is defined as yield of functional group in ${ }^{13} \mathrm{C}$ labeled experiment $(\mathrm{g} / 100 \mathrm{~g}) /$ yield in unlabeled experiment $(\mathrm{g} / 100 \mathrm{~g})=[(\%$ distribution in labeled experiment $(\mathrm{g} / 100 \mathrm{~g}) \times$ fraction of label enhancement in glucose, 0.99) / (\% distribution in unlabeled experiment $(\mathrm{g} / 100 \mathrm{~g}) \times$ fraction of natural label enhancement $\left(0.011\right.$ for ${ }^{13} \mathrm{C}$ in natural glucose $\left.)\right)$ ].

${ }^{\mathrm{b}}$ approximate, trace only 


\section{ORGANIC FRACTIONATION}

\subsection{Organics in red mud}

During the digestion stage of the Bayer process, most organics in the bauxite dissolve but some organic material is insoluble. The insoluble organic matter is removed from the process with the red mud waste product, as an organic rich material on heater tubes in the shell-side of heat exchangers, or adsorbed on aluminium hydroxide precipitate and the sodium oxalate by-product. Sometimes organic matter is also observed in precipitation tank scale and with oxalate-gibbsite co-precipitated fine particles.

It is worthwhile observing the differences in chemical structure between the organic matter that was insoluble in sodium hydroxide that ends up in the red mud, with the organic material in the original bauxite as this provides an insight into the changes taking place during digestion. However, simple pyrolysis-GC/MS is insufficient to compare the two components in the red mud and bauxite because the iron oxide, but not the alumina species, catalyses the decomposition of the organics $/ 31 /$.

The methanol soluble products are different in the red mud and bauxite as shown by pyrolysis. The pyrolysis products from the methanol solubles from the red mud contained various alkanes, alkenes, aromatic carboxylic acids, and aliphatic carboxylic acids. Some examples include methyl benzoate, methyl esters of saturated $C_{4}-C_{20}$ carboxylic acids and $C_{11}-C_{23}$ alkenes. Few aromatic compounds were seen in the extracts $/ 31 /$. Some of the species released from the red mud were also released from the bauxite when it was analysed under the same conditions, however the compounds were present in very different amounts. These results highlight that the composition of the organic materials in the bauxite and red mud are intrinsically different.

It is clear from the above results that the dissolution of organic matter in the Bayer process is selective. That is, the molecular structure of the organic matter in the red mud differs from that in the bauxite and also from the soluble compounds that dissolve in the Bayer liquor. Surprisingly some of the most polar compounds including the short chain carboxylic acids concentrate in the red mud despite their solubility in sodium hydroxide. These results suggest that the red mud acts as an adsorbent for these compounds. 


\subsection{Other insoluble organics}

As noted in Section 3.1, insoluble organic material (Table 3) is removed at several other stages of the Bayer process including as an organic rich material on heater tubes in the shell-side of heat exchangers, on aluminium hydroxide precipitated crystals, the sodium oxalate by-product, as well as in precipitation tank scale and with oxalate-gibbsite co-precipitated fine particles.

After digestion, the first cooling event occurs at the heat exchanger units. Here an organic material forms on the shell-side of heater tubes and contains enough carbon to be analysed by ${ }^{13} \mathrm{C} \mathrm{CP/MAS} \mathrm{NMR}$. The material is highly aromatic, and the aromaticity [fraction of carbon that is aromatic, $\left(f_{a}\right)$ ] is 0.40 131 . The absence of carboxylic carbon at or about $175 \mathrm{ppm}$ chemical shift shows that this material is not humic like. Pyrolysis-GC/MS data on the same material identified the sample as having the composition of a light pitch or tar.

Solid-phase sodium oxalate plays a minor role in the sodium content of product alumina, but it has a critical role in gibbsite nucleation in precipitation operations, determining crystal size and particle numbers $15,6 /$. The presence of organic matter in the Bayer liquor stabilises the oxalate in solution to some extent; however, once oxalate precipitation begins the oxalate surface adsorbs some of the organics from the liquor promoting further precipitation. This phenomenon, known as 'oxalate showers', disturbs the orderly precipitation of aluminium hydroxide, causing excess nucleation leading to fines in the circuit and poor quality alumina with a high sodium content $15,6 /$. Most alumina refineries use an oxalate removal circuit to control the process and minimise the impact of this material. As a result, the crystallised oxalate is also a material that removes insoluble organic material from the Bayer process.

Crystallised aluminium hydroxide also contains insoluble organic material. These aluminophilic organics play a role in the poisoning of the Bayer process by altering the growth of gibbsite crystals from the Bayer liquor.

The solid state ${ }^{13} \mathrm{C}$ NMR spectra of the insoluble carbon in the sodium oxalate and aluminium hydroxide are similar. The NMR spectra contain three main regions - a distinct aromatic region (100-150 ppm), a less intense aliphatic region consisting of carbon substituted with electron donating groups (50-100 ppm) and a series of peaks in the region between 160-180 
Thelma J. Whelan et al.

Reviews in Chemical Engineering

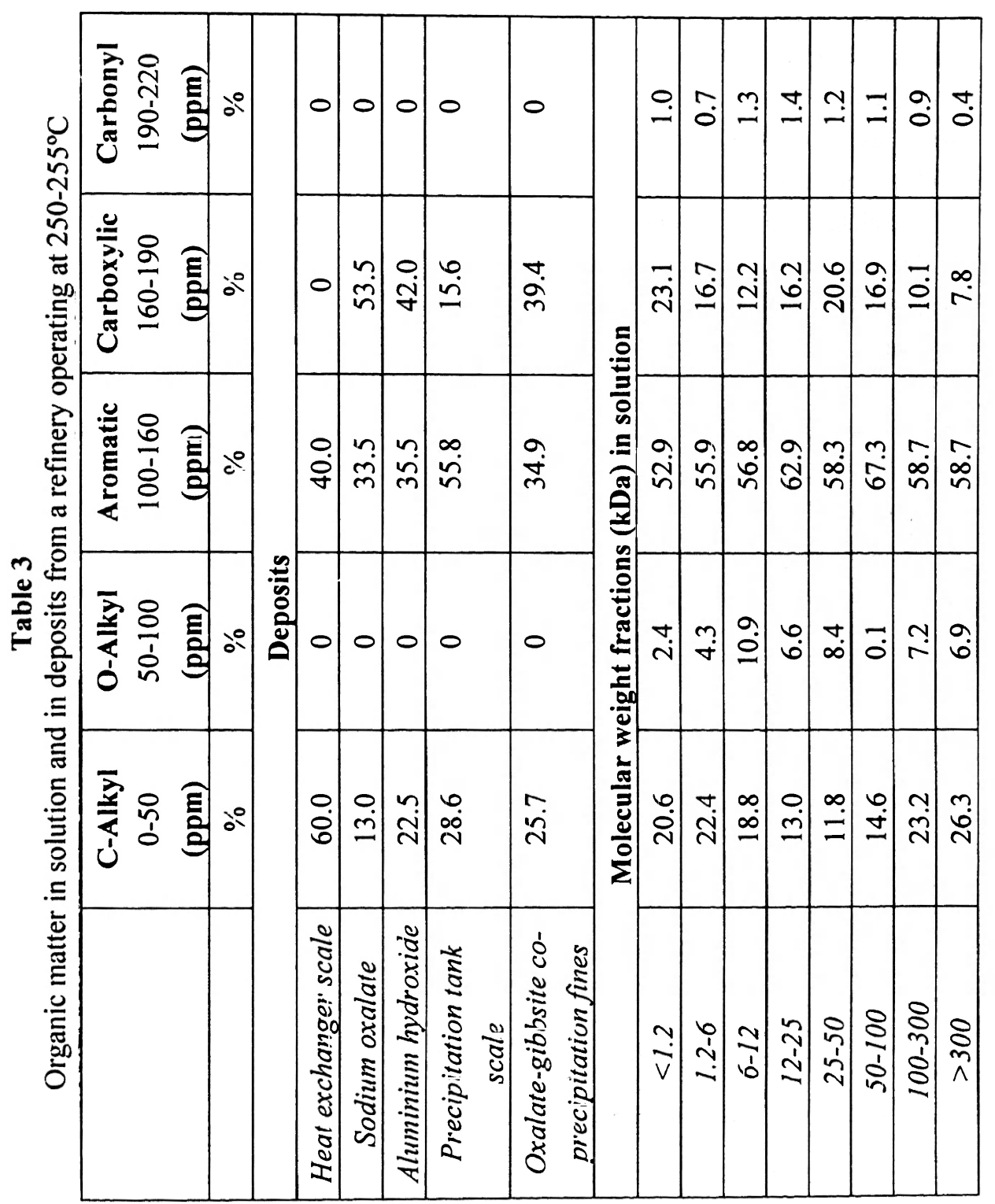


ppm due to the presence of carboxylic carbon and oxalate $/ 31 /$.

Sodium oxalate and aluminium hydroxide produced several common pyrolysis products including alkanes, alkenes and long chain aliphatic carboxylic acids (predominantly with $\mathrm{C}_{14}$ to $\mathrm{C}_{16}$ carbon chain lengths), as well as short chain $\left(\mathrm{C}_{4}-\mathrm{C}_{7}\right)$ aliphatic mono-, di- and tri- carboxylic acids. The main difference is that the aluminium hydroxide pyrolysates also contain large amounts of fluorene, biphenyl and methyl-substituted naphthalenes, as well as low concentrations of methyl-substituted phenanthrenes and anthracenes and two alkanes, $\mathrm{C}_{20}$ and $\mathrm{C}_{21}$.

Oxalate-gibbsite co-precipitation fines are a network of aluminium hydroxide and sodium oxalate crystals that do not settle from the Bayer liquor. This product gave pyrolysis products including alkanes, alkenes, aromatic compounds including substituted benzenes, alkylbenzenes, napthalenes as well as substituted anthracenes, phenanthrenes and fluorenes. The solid state ${ }^{13} \mathrm{C}$ NMR spectrum of the oxalate-gibbsite co-precipitation fines showed the presence of aliphatic and aromatic carbon. NMR spectra of oxalate-gibbsite co-precipitation fines show a range of structural groups including aromatic and methoxy $/ 31 /$. The presence of such a wide range of chemical groups may poison further precipitation and growth of the crystals. This may explain why the crystals of aluminium hydroxide and sodium oxalate fines were prevented from growing sufficiently large to be settled from the Bayer process by gravity separation.

Precipitation tank scale contains both precipitated sodium oxalate and aluminium hydroxide. The ${ }^{13} \mathrm{C}$ NMR spectrum of the precipitation tank scale appeared quite similar to the NMR spectra obtained for dissolved humic substances with the proportions of the different carbon types also being similar $/ 31 /$.

\section{ORGANICS IN SOLUTION}

\subsection{Process differences due to temperature}

Typical concentrations of organics in Bayer liquors which are extracted from the bauxite into the Bayer process liquor during digestion range from a few grams per litre up to $40 \mathrm{~g} / \mathrm{L}, / 5 /$ and they have molecular weights from less than $100 \mathrm{Da}$ to greater than $300 \mathrm{kDa} / 32,33 /$. As already noted this geoorganic matter causes numerous problems in the operation of alumina 
refineries. The compositions of organic materials obtained from a low temperature Bayer refinery $\left(145-150^{\circ} \mathrm{C}\right)$ and a high temperature refinery $\left(250-255^{\circ} \mathrm{C}\right)$ have been compared $/ 32,33 /$.

Typical chemical compositions of the organic molecular weight fractions are detailed in Tables 3 and 4 but they vary with refinery /32, 33/. Table 4 also shows compositions of whole liquor organics prior (pregnant) and post (spent) precipitation of alumina hydrate. Table 4 shows the smallest molecular weight fraction, the $<1.2 \mathrm{kDa}$ fraction, accounting for $87 \%$ of the recovered organic material from a refinery operating at $250-255^{\circ} \mathrm{C}$. Structurally the $<1.2 \mathrm{kDa}$ fraction contains mainly hydroxybenzene carboxylic acids $/ 32,33 /$. The $12-25 \mathrm{kDa}$ and $25-50 \mathrm{kDa}$ fractions appear to resemble material more akin to kerogen, while the highest molecular weight organic material $(>300 \mathrm{kDa}$ ) behaves as a soluble char $/ 32,33 /$.

Table 4 shows that the acidities of the organic fractions are highly variable. The two whole organic fractions, from the pregnant and spent liquors, as well as the $<1.2 \mathrm{kDa}$ fraction are the most acidic. The $\mathrm{pH}$ of each fraction generally increases with increasing molecular weight; however, the $12-25 \mathrm{kDa}$ fraction is an exception. Acidity of the fractions is an important factor during precipitation testing as this affects local ionic strengths of the Bayer solutions, which has an impact on oxalate stability, and precipitation yields.

\subsection{Small molecular weight molecules}

The amount of less than $1.2 \mathrm{kDa}$ molecules is highly dependent on temperature, bauxite geological history and species of native plant matter as previously described. This is the most acidic fraction containing the highest proportion of carboxylic carbon $\left(20 \%, 145^{\circ} \mathrm{C}\right.$ and $\left.23.1 \%, 245^{\circ} \mathrm{C}\right)$, compared with $>300 \mathrm{kDa}$ higher molecular weights $\left(9.8 \%, 145^{\circ} \mathrm{C}\right.$ and $\left.7.8 \%, 245^{\circ} \mathrm{C}\right)$ /15.18/. Much of this fraction comprises of very low molecular weight species, such as, oxalate and lactic, acetic and formic acids and a range of benzene carboxylic acids /5-7/. They are well documented by Lever /34/. Table 5 shows comparative py-GC/MS data between compounds found in the lowest molecular weight fraction isolated from a low temperature $\left(145^{\circ} \mathrm{C}\right)$ $132 /$ and high temperature $\left(245^{\circ} \mathrm{C}\right) / 33 /$ processes which shows clear differences in volatiles upon pyrolysis.

It is clear that the presence and thus the formation of compounds in the low molecular weight fractions isolated from Bayer liquors are Bayer plant 
Table 4

Yields, acidity and elemental analysis of the Bayer humic substance fractions (dry ash free basis) from a refinery operating at $250-255^{\circ} \mathrm{C}$

\begin{tabular}{|c|c|c|c|c|c|c|c|c|c|c|c|c|}
\hline $\begin{array}{c}\text { Fraction } \\
\text { No. }\end{array}$ & $\begin{array}{c}\text { Molecular } \\
\text { weight fracticn } \\
(\mathrm{kDa})\end{array}$ & $\% \mathrm{C}$ & $\% \mathbf{H}$ & $\% N$ & $\% S$ & $\begin{array}{c}\% O \\
\text { Diference }\end{array}$ & $\mathrm{O} / \mathrm{C}$ & H/C & N/C & $\mathrm{S} / \mathrm{C}$ & $\begin{array}{c}\mathrm{pH} \text { at } \\
5 \mathrm{~g} / \text { litre in } \\
\text { water }\end{array}$ & $\begin{array}{c}\text { Mass yield } \\
(\%)^{\mathrm{a}}\end{array}$ \\
\hline $\mathrm{PL}^{b}$ & $<1.2$ to $>300$ & 56.32 & 3.67 & 0.36 & 0.23 & 39.42 & 0.53 & 0.78 & 0.0055 & 0.0015 & 2.43 & 100.00 \\
\hline $\mathrm{SL}^{\mathrm{b}}$ & $<1.2$ to $>300$ & 53.13 & 3.58 & 0.11 & 0.11 & 43.07 & 0.61 & 0.80 & 0.0018 & 0.00078 & 2.39 & 100.00 \\
\hline 1 & $<1.2$ & 50.79 & 4.22 & 0.56 & 0.17 & 44.26 & 0.65 & 0.99 & 0.0095 & 0.0013 & 2.48 & 87.0 \\
\hline 2 & $1.2-6$ & 48.25 & 3.78 & 1.87 & 0.32 & 45.78 & 0.71 & 0.93 & 0.033 & 0.0025 & 2.96 & 3.3 \\
\hline 3 & $6-12$ & 54.32 & 4.23 & 3.22 & 0.60 & 37.62 & 0.52 & 0.93 & 0.051 & 0.0041 & 3.39 & 0.6 \\
\hline 4 & $12-25$ & 53.87 & 3.67 & 1.39 & 0.44 & 40.62 & 0.57 & 0.81 & 0.022 & 0.0031 & 2.90 & 1.6 \\
\hline 5 & $25-50$ & 55.58 & 5.41 & 3.69 & 0.42 & 34.90 & 0.47 & 1.16 & 0.057 & 0.0028 & 3.79 & 1.0 \\
\hline 6 & $50-100$ & 48.85 & 4.05 & 4.92 & 0.68 & 41.50 & 0.64 & 0.99 & 0.086 & 0.0052 & 3.99 & 3.8 \\
\hline 7 & $100-300$ & 49.13 & 4.85 & 5.92 & 0.99 & 39.11 & 0.60 & 1.18 & 0.10 & 0.0075 & 4.64 & 0.7 \\
\hline 8 & $>300$ & 54.52 & 3.78 & 2.05 & 0.42 & 39.24 & 0.54 & 0.83 & 0.032 & 0.0029 & 4.36 & 2.0 \\
\hline
\end{tabular}

a) The weight of fraction over total weight of material recovered. $b$ ) $\mathrm{PL}=$ pregnant liquors, $\mathrm{SL}=$ spent liquors 
Table 5

Comparison of py-GC/MS data at $450^{\circ} \mathrm{C}$ between low molecular weight $(<1.2 \mathrm{kD})$ fraction from a low temperature and high temperature Bayer liquor. Selective relative abundance (\%) to phenol.

\begin{tabular}{|c|c|c|}
\hline Compound & $\begin{array}{c}\text { Low } \\
\text { temperature } \\
\text { process }\left(145^{\circ} \mathrm{C}\right) \\
<1.2 \mathrm{kD} \\
\end{array}$ & $\begin{array}{c}\text { High temperature } \\
\text { process }\left(245^{\circ} \mathrm{C}\right) \\
<1.2 \mathrm{kD}\end{array}$ \\
\hline Toluene & 35.3 & \\
\hline 1,2-dimethylbenzene & 44.9 & \\
\hline 1,2,3-trimethylbenzene & 27.7 & \\
\hline 5-methoxy-2-methyl-1H-indole & 90.1 & 99 \\
\hline 4-hydroxybenzonitrile & & 51 \\
\hline Phenol & 100 & 100 \\
\hline 2-methylphenol & 16.8 & \\
\hline 3-methylphenol & 31.8 & \\
\hline 2-methoxyphenol & 55.5 & \\
\hline 2-naphthalenol & & 125 \\
\hline 2-coumaranone & 54.4 & 63 \\
\hline 2-methyl -1,3-isobenzofurandione & & 61 \\
\hline 4-hydroxyphenyl-1-pentanone & & 23 \\
\hline $1 \mathrm{H}$-isoindole- $1,3(2 \mathrm{H})$-dione & & 87 \\
\hline $\begin{array}{l}\text { 4,7-dimethyl-1,3- } \\
\text { isobenzofurandione }\end{array}$ & & 170 \\
\hline $\begin{array}{l}\text { 5,6-dimethyl-1,3- } \\
\text { isobenzofurandione }\end{array}$ & & 59 \\
\hline Benzoic acid & 50.1 & 83 \\
\hline 3-methylbenzoic acid & 29.2 & 41 \\
\hline 4-methylbenzoic acid & 34.0 & \\
\hline $\begin{array}{l}\text { 4-methyl-1,2-benzenecarboxylic } \\
\text { acid }\end{array}$ & & 100 \\
\hline 3-hydroxy-4-methylbenzoic acid & & 287 \\
\hline Trimethylbenzaldehyde & 49.3 & \\
\hline
\end{tabular}


dependent. Interestingly, Table 5 shows that the high temperature process contains a higher proportion of ketones, diones and nitrogen containing compounds. This is in contradiction with the low temperature process in which methylbenzenes, phenols, and benzoic acids predominate. Temperature may play a role in this discrepancy, in that high temperatures produce more highly oxidised species. However, it is also likely that the differing geo-histories of the bauxite deposits produce different organic inputs to the processes.

\subsection{Intermediate molecular weight molecules}

There is little literature on the interaction of intermediate $(1.2-100 \mathrm{kDa})$ molecular weight humic substances with alumina, although it is known that this material plays an important role in the Bayer process.

Attempts have been made to characterise and quantify these intermediate organic molecules present in the Bayer liquor by using a number of chromatographic techniques. GC-MS spectral analysis has been successfully used to identify and quantitate a number of smaller molecular components such as monocyclic aromatic carboxylic acids and alkanes and fatty acids 132,33/. Liquid chromatographic (LC) analysis of the humic acid component has been less successful. LC methods for the monitoring of known organic and inorganic ions that accumulate in the process liquor have been reported 135- 37/. Any further reported attempts at analysing the humic acids found in the Bayer liquor have been restricted to the quantitative analysis of the humic acids present 138/. The development of a High-Performance Liquid Chromatographic (HPLC) method for resolving these intermediate molecular weight components into molecular entities or even compound classes would be of considerable industrial importance $139,40 /$. Two-dimensional HPLC methods show promise.

\subsection{Large molecular weight molecules}

The higher molecular weight organics $(>50 \mathrm{kDa})$, although present in low concentrations in Bayer process liquor, have a range of structures. The largest are char like /15-18/. In principle because they are large compounds it would be expected that these would have large surface covering effects and therefore inhibit precipitation in this way. As hosts they may also contain many guests, which might be prevented from playing a role in precipitation. 
They can effectively alter the equilibrium concentration between an adsorbing guest on a crystal surface and a free guest in solution. Char like materials can be in the original bauxite /18/ but solubility studies suggest this material ends up largely as insolubles in the red mud. Thus char like materials are probably also synthesised in the process.

\subsection{Host guests in Bayer liquor extracts}

It is clear that a myriad of chemical compounds of different molecular weights compose the organic mixture that makes up the organic matter in Bayer liquors. Many have extremely high molecular weights with values for some components as high as $300 \mathrm{kDa}$. Dialysis of humic organic matter separates the material into molecular weight fractions or more correctly, fractions that can pass through specifically sized pores. Despite attempts to separate organic matter into molecular weight fractions by dialysis, specific higher molecular weight fractions were obtained which still contained low molecular weight organic material. Material of molecular weight of $50 \mathrm{kDa}$ or greater will have voids in its packing quite capable of occluding smaller molecular weight material so that the smaller materials are in fact guests. It was clear that these small molecules appeared to be bound to much larger macromolecules by physical entrapment and/or hydrogen bonding.

One new finding for oxidising environments is the concept of host-guest structures where smaller molecules reside within a framework of a macromolecular host primarily derived from lignin $/ 41 /$. The guests within the host cannot be removed by physical separation techniques. The structure of the host can be determined by py-GC/MS and NMR techniques. Differential thermal analysis, calorimetry, methylation and NMR data can be used to identify the guests. Some of the guests are probably held by hydrogen bonding but others are true prisoners in that they are alkanes and hence have no binding sites.

In differential thermal gravimetric analysis studies on various dialysed high molecular weight $(>25 \mathrm{kDa})$ fractions, the loss of mass up to $200^{\circ} \mathrm{C}$ was attributed to loss of volatile organics as well as surface and bound water $133,41 /$. These molecules are trapped in the macromolecular matrix. If the amount of water and volatile organics adsorbed on a humic extract solid is calculated and compared with that calculated by summing that for each molecular weight fractions adjusted for mass, the numbers differ. This shows that the water and volatile organic holding capacity for the different fractions 
changes when the different molecular weight materials are separated. It suggests that the various humic molecular weight fractions agglomerate together in structures where some of the water or volatile organic binding sites, on each humic substance, are held by other humic species. This is depicted in Figure 2 (left side), where both water and small organic volatiles (circles) occupy binding sites and the bound molecules can bridge macromolecules (rectangles). After separation by dialysis (Figure 2, right side) the large molecules are separated and this process generates more sites for adsorption of small molecules. Thus the water and volatile content of the unseparated material is not the same as the mass weighted sum of the water content of the separated materials. Mass loss data expressed as first derivative plots (differential thermal gravimetric analysis, DTG) indicates temperatures at which rapid mass loss occurred and this allows further information to be gained. Such plots also show that secondary volatile material is present which gives superimposed inflections in DTG plots.

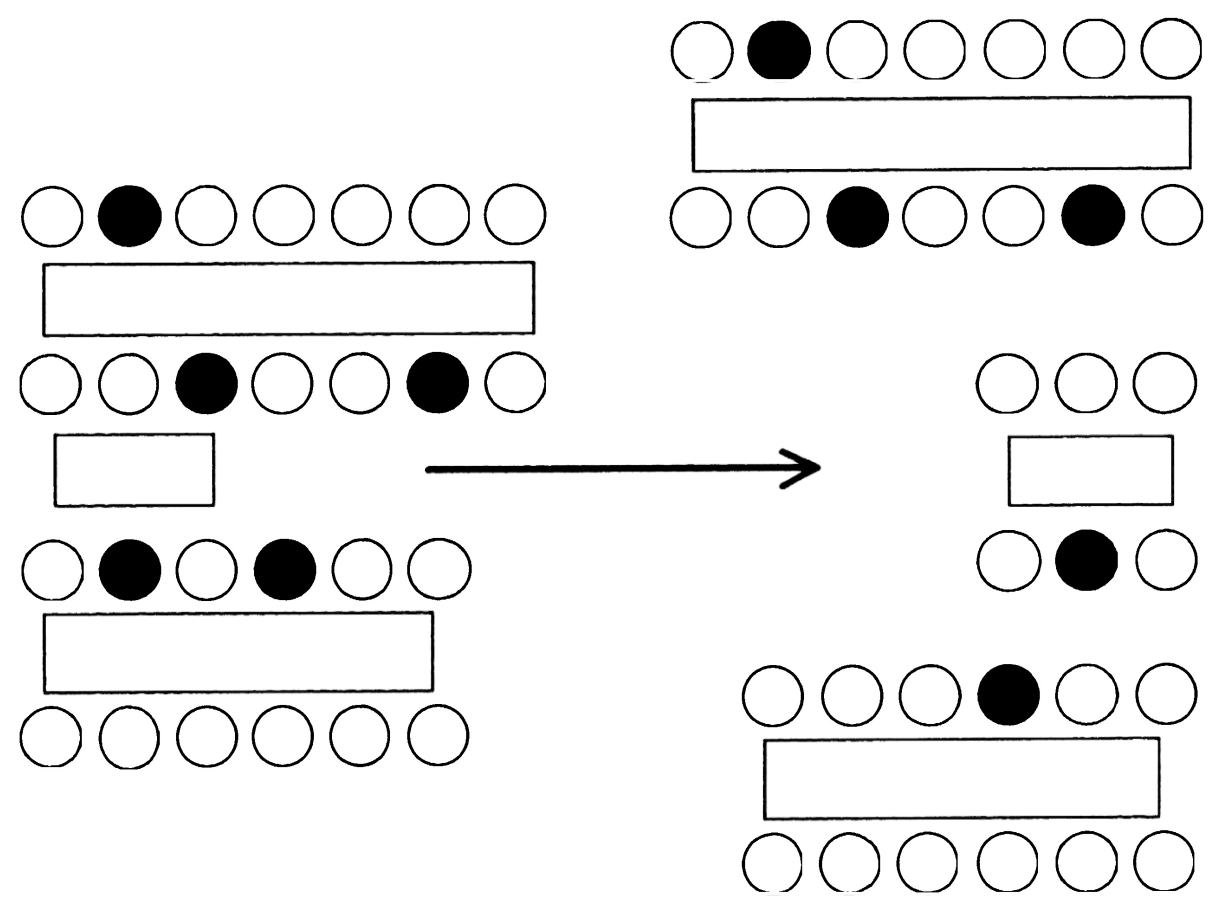

Fig. 2: Model to explain the water and volatile holding capacity of humic substances before and after fractionation. Rectangles = humic substance, length equivalent to molecular weight, $\mathrm{o}=$ water, $\bullet=$ organic volatile. The arrow represents the process of dialysis. 
Enthalpy can also assist in identification. However, thermal events are not discrete for geo-organic matter, since a variety of materials may be volatilising at the same time or changing phase in some other way. Since the $\Delta \mathrm{H}$ of vaporisation of water is known $\left(44 \mathrm{~kJ} \mathrm{~mol}^{-1}\right)$, it is possible to determine whether the thermal events at lower temperatures are due to loss of water or not. Thus there is considerable evidence for volatile material other than water being present from enthalpy data. This is additional evidence that the events are evaporations and not decompositions and arise from trapped species.

${ }^{1} \mathrm{H}$ and ${ }^{13} \mathrm{C}$ NMR analysis of molecular weight fractionated material is very useful in supporting this proposition $/ 41 /$. Discrete resonances should not be observed for macromolecules, yet they are seen in high molecular weight fractions. In larger molecular weight fractions these are mainly confined to the aliphatic region. The ' $\mathrm{H}$ NMR spectrum of all fractions of molecular weight greater than $25 \mathrm{kDa}$ showed few discrete resonances in the aromatic region. These fractions $>25 \mathrm{kDa}$ appear to form molecular aggregates with alkanes and aliphatic fatty acids. Discrete aromatic resonances were not seen for $>300 \mathrm{kDa}$ molecular weight fractions, indicating that there were no small aromatic compounds in this fraction.

When the fractions were methylated with tetramethyl ammonium hydroxide (TMAH) /42/ and subsequently analysed by GC/MS, a wide variety of compounds were identified including benzenecarboxylic acids, $\boldsymbol{n}$ alkanes, and fatty acids. These three families of compounds represented the majority of the compounds released by the fractions. Many of the compounds released from the Bayer organic fractions by methylation were analysed as methyl esters, particularly the fatty acids and benzenecarboxylic acids.

Methylation with TMAH acts to release small molecules trapped in the macromolecules by forming esters and ethers with carboxylic and phenolic groups respectively, thereby breaking the hydrogen bonding that holds the molecules in place. Without methylation the molecules are held tightly in the macromolecular matrix. When the un-methylated fractions were analysed by GC/MS no small molecules were detected; only the internal standard $\left(\mathrm{C}_{20}\right)$ was identified. This result indicates that the small molecules are tightly hydrogen bonded in the macromolecule structures by forming molecular aggregates.

n-Alkanes were identified in the chromatograms of the methylated fractions with carbon chain lengths ranging from CI 1 to C29. n-Alkanes are derived from algal, microbial and higher plant sources. The distribution of the $n$-alkanes in these fractions suggests that they were derived from the 
waxes of higher plants. Fatty acids were found to be one of the main chemical classes released by the methylation of the Bayer organic fractions. Fatty acids with carbon chain lengths ranging from $\mathrm{C} 7$ to $\mathrm{C} 22$ were identified as products of the fractions. Fatty acids that were identified were found to have both monocarboxylic and dicarboxylic acids on their structures as well as unsaturations in several of the products. Numerous $\mathrm{C} 18$ isomers were identified as products from the organic fractions. Numerous substituted benzene mono- and di-carboxylic acid compounds were identified as methylation products from the Bayer organic fractions.

It is not clear that the host-guest complexes formed by these highly oxidised humic molecules also exist in solution. The deprotonated conjugate bases, phenoxide and carboxylate would not form strong hydrogen bonds under these conditions due to repulsion forces of similarly charged species under strongly basic conditions but under neutral $\mathrm{pH}$ they may still hydrogen bond. In either case, during precipitation intra molecular hydrogen and intermolecular hydrogen bonding may occur. In the process large molecules voids may be formed which could occlude other molecules. It may well be true that some of these occluded molecules also hydrogen bond but the presence of alkanes shows that for some molecules this is not always the case.

\section{POISONING}

\subsection{Ionic strength effects}

In high ionic strength solutions molecules do not behave as free ions but exist in tight ion pairs. Thus in Bayer solutions the surface probably resembles the sort of phenomenon that exists in an electrical double layer at a surface or in molten salts. In this process the adsorption of an ion results in the immediate replacement of it with another of same charge from further out in solution. The kinetics of adsorption are dependent on interactions between ions not just the interaction with the surface. Likewise in nucleation the forces acting in chelation are different because molecules must move in tightly bound ion pairs. Thus it is not possible to directly extrapolate the effects of various ion concentrations without understanding activity. Poisoning experiments must be done at constant ionic strength if the effects of activity changes are not to be observed. Examples are cases where a 
carboxylic acid might locally consume hydroxide ion, thereby altering the local ionic strength, and thus the effect on alumina hydrate yield is due to an ionic strength change and not due to adsorption.

\subsection{Aluminophilicity and poisoning}

By aluminophility we mean the desire for a molecule to adsorb on the alumina surface. It has been shown conclusively that this does not correlate with poisoning activity /43/. This is clear evidence for a role of organic matter in influencing nucleation rather than just altering surface coverage.

\subsection{Precipitation experiments}

Table 6 illustrates typical poisoning experiments /44,45/. The first set of experiments (Group A) was run with the organic fractions added at the concentrations recovered from the process using caustic washed seed. This was obtained by taking the seed crystal slurry from the refinery and extensively (5x) washing it with hot $\sim 5 \mathrm{M} \mathrm{NaOH}$, and then water rinsed and air-dried. The second sets of experiments (Group B) were performed with equal concentrations of the organic fractions (Table 7) and hot water washed seed (seed crystals were prepared by five hot water washings of typical refinery seed).

Experiments were carried out under model conditions in which Bayer refinery additives were present such as carbonate oxalate and chloride ions 144, 45/. Different molecular weight fractions of the humic substances were found to have different detrimental affects on precipitation yields of aluminium hydroxide and these did not correlate with changes in crystal surface area.

The results for Group A experiments (Table 6) conducted with the organic fractions at the concentrations recovered from the Bayer process liquor showed few negative impacts from the presence of the organics. Table 6 shows little inhibition of the precipitation of aluminium hydroxide, with the yields of aluminium hydroxide for samples containing organic species being almost identical to the blank sample. In some cases the yield was higher than the blank, possibly as a result of the humic acids decreasing the concentration of the sodium hydroxide by protonation of hydroxide ion, thereby providing a greater driving force for precipitation and therefore higher precipitation yields. The largest decrease in yield was observed for the 12-25 kDa fraction 
Table 6

Results from dose rate experiments with humic molecular weight fractions under pseudo-Bayer plant conditions (Group A experiments) on aluminium hydroxide precipitation using caustic-washed seed

\begin{tabular}{|l|c|c|c|c|c|}
\hline $\begin{array}{c}\text { Organic } \\
\text { fraction }\end{array}$ & $\begin{array}{c}\text { Organic dose } \\
(\mathbf{g} / \mathbf{L})\end{array}$ & $\begin{array}{c}\text { Difference in } \\
\text { yield of alumina } \\
\text { (g) relative to } \\
\text { blank }\end{array}$ & $\begin{array}{c}\text { \% Change in } \\
\text { product with } \\
\text { surface area } \\
<\mathbf{2 0} \boldsymbol{\mu \mathbf { m } ^ { 2 } \text { relative to }} \\
\text { blank }\end{array}$ & $\begin{array}{c}\text { \% Change in } \\
\text { surface area of } \\
\text { product relative to } \\
\text { blank }\end{array}$ & $\begin{array}{c}\text { \% Change in } \\
\text { oxalate } \\
\text { concentration } \\
\text { relative to blank }\end{array}$ \\
\hline$<1.2 \mathrm{kD}$ & 2.48 & 0.86 & +0.79 & -0.82 & +11.20 \\
\hline $1.2-6 \mathrm{kD}$ & 0.095 & 0.12 & +0.66 & +4.06 & -8.86 \\
\hline $6-12 \mathrm{kD}$ & 0.018 & -0.05 & +0.57 & +3.25 & -12.68 \\
\hline $12-25 \mathrm{kD}$ & 0.046 & -0.43 & +0.05 & +9.76 & -12.73 \\
\hline $25-50 \mathrm{kD}$ & 0.018 & 0.08 & +0.32 & -6.50 & -6.69 \\
\hline $50-100 \mathrm{kD}$ & 0.108 & -0.01 & +0.14 & -2.80 & +11.10 \\
\hline $100-300 \mathrm{kD}$ & 0.020 & 0.56 & +0.16 & -0.82 & +15.00 \\
\hline$>300 \mathrm{kD}$ & 0.065 & 0.54 & +0.23 & -0.82 & +8.60 \\
\hline
\end{tabular}


Table 7

Results from constant dose rate experiments with humic molecular weight fractions at $0.1 \mathrm{~g} / \mathrm{L}$

(Group B experiments) on aluminium hydroxide precipitation using hot water washed seed

\begin{tabular}{|l|c|c|c|c|c|}
\hline $\begin{array}{c}\text { Organic } \\
\text { fraction }\end{array}$ & $\begin{array}{c}\text { Organic dose } \\
(\mathbf{g} / \mathbf{L})\end{array}$ & $\begin{array}{c}\text { Difference in } \\
\text { yield of } \\
\text { alumina }(\mathrm{g}) \\
\text { relative to } \\
\text { blank }\end{array}$ & $\begin{array}{c}\text { \% Change in } \\
\text { product with } \\
\text { surface area } \\
\mathbf{2 0} \boldsymbol{\mu \mathbf { m } ^ { 2 } \text { relative }} \\
\text { to blank }\end{array}$ & $\begin{array}{c}\text { \% Change in } \\
\text { surface area of } \\
\text { product relative } \\
\text { to blank }\end{array}$ & $\begin{array}{c}\text { \% Change in } \\
\text { oxalate } \\
\text { concentration } \\
\text { relative to blank }\end{array}$ \\
\hline$<1.2 \mathrm{kD}$ & 0.1 & -0.11 & +3.16 & -16.65 & 0 \\
\hline $1.2-6 \mathrm{kD}$ & 0.1 & -0.31 & -2.68 & +27.30 & +0.40 \\
\hline $12-25 \mathrm{kD}$ & 0.1 & -0.75 & -2.91 & +28.87 & +3.66 \\
\hline $50-100 \mathrm{kD}$ & 0.1 & -0.71 & -2.87 & +28.63 & +9.40 \\
\hline$>300 \mathrm{kD}$ & 0.1 & -1.68 & -1.70 & +20.46 & +16.60 \\
\hline
\end{tabular}


$(-0.43 \mathrm{~g})$ which appears to have quite different properties from the other organic fractions.

Table 6 shows no correlation between surface area of crystals and the yield. However the greatest increase in surface area was exhibited by the 12$25 \mathrm{kDa}$ fraction which also inhibited the yield the most. The 25-50 kDa fraction produced a decrease in surface area. These results do not translate directly to particle size because of agglomeration and microcavities. All fractions increased the percentage of very fine crystals with surface areas less than $20 \mu \mathrm{m}^{2}$, with the largest increase seen for the $<1.2 \mathrm{kDa}$ fraction. This fraction produced a $0.79 \%$ increase in the amount of fine material. Interestingly the $12-25 \mathrm{kDa}$ fraction, which reduced yield and increased surface area, produced the smallest change in very fine crystals. Thus the role of these small and intermediate molecular weight organics is complex and is not simply one of inhibiting growth of crystals. Rather they also affect nucleation and agglomeration as well as growth in rather subtle ways.

Group B experiments used hot water washed seed crystals to promote crystallisation, Each fraction clearly had an effect on yield (Table 7), with the least poisonous fraction being the $<1.2 \mathrm{kDa}$ fraction. However, although the small molecular weight material did not strongly affect the yield of aluminium hydroxide crystals, the $<1.2 \mathrm{kDa}$ fraction had a strong influence on crystal size, decreasing the surface area of the product aluminium hydroxide while increasing the amount of very fine crystals $\left(20 \mu \mathrm{m}^{2}\right)$.

It is clear from Table 7 that the higher molecular weight organics $(>12$ $\mathrm{kDa}$ ), although present in low concentrations in Bayer process liquor, have particularly strong adverse affects on the precipitation of aluminium hydroxide. Group B experiments showed that the higher molecular weight humic materials acted as precipitation poisons with the most poisonous fraction being the $>300 \mathrm{kDa}$ material (Table 7).

Table 7 showed that, although the yield of the aluminium hydroxide product was decreased by the larger humic material, the material actually increased the size of the precipitated crystals by increasing the surface area of the crystals and decreasing the amount of very fine crystals. In addition, Tables 6 and 7 showed that the larger molecular weight humic materials also have an important role to play in oxalate stability. All fractions $>50 \mathrm{kDa}$ substantially increased the concentration of oxalate in solution with the $>300$ $\mathrm{kDa}$ fraction having the largest effect. These higher molecular weight organic fractions increased oxalate stability in synthetic Bayer liquor by up to $20 \%$ (see below, section 5.5). 


\subsection{Stressed systems}

Mitchell et al. /46/ discovered that precipitation yields could be improved if poisoning organic species were adsorbed onto calcined alumina. Caustic washing of the seed crystals was examined to determine whether the creation of a clean crystal surface through the dissolution of the outer crystal layers, along with contaminating organics, would act to improve precipitation yields by providing sites for the poisoning organics to bind. Caustic seed washing would provide a greater number of binding sites for poisoning organic species to adsorb while still providing free precipitation sites to allow precipitation to continue.

The effects of various molecular weight fractions $(<1.2 \mathrm{kDa}$ to $>300 \mathrm{kDa})$ of organic matter on precipitation yields were maximised under system stress. That is, when there is competition for the number of sites at which new alumina carrying species or humic material can bind the impact on precipitation is increased, as a result the organic fractions impacted strongly on precipitation when hot-water washed seed was used. The preparation of seed crystal is therefore very important and because of competition, effects are concentration dependent.

These concepts are supported by comparative experiments on seed. Group A experiments with caustic washed seeds show a much greater tolerance to humic material which suggests that caustic washing increases the number of sites at which new alumina carrying species or humic materials can bind. Thus if humic materials bind there are plenty of sites left to grow alumina. Indeed Group A experiments (caustic washed seed) showed much less variation in the surface area of the product crystals. Group A experiments showed a maximum change in the surface area of the product crystals of $\pm 10 \%$, with many organic fractions producing a change of less than $4 \%$ (Table 6). From these results it appears that changes in surface area can be minimised through the use of caustic washed seed, which may negate many of the detrimental impacts of the poisoning organic species.

\subsection{Sodium Oxalate}

Solid-phase sodium oxalate plays a minor role in the sodium content of product alumina, but has a critical role in gibbsite nucleation and fines balance in precipitation operations, determining crystal size and particle numbers $15,6 /$. Bayer alumina refineries typically operate an oxalate 
precipitation stage to control the level of oxalate build up in the liquor, so as to minimise the impact of this organic degradation product via precipitation at unwanted parts of the process. The presence of organic matter in the Bayer liquor stabilises the oxalate in solution to some extent $/ 45 /$. However, once oxalate precipitation begins the oxalate surface adsorbs some of the organics from the liquor, promoting further precipitation. This phenomenon disturbs the orderly precipitation of aluminium hydroxide, causing excess nucleation leading to fines in the circuit and poor quality alumina with a high sodium content $/ 5,6 /$.

Table 6 shows results from the oxalate concentrations in the Group A experiments (caustic washed seed). They reveal that the small molecular weight organic species $(<50 \mathrm{kDa})$ decreased oxalate stability by up to $13 \%$, with the exception being the $<1.2 \mathrm{kDa}$ fraction that showed a slight increase in oxalate stability (11\%). These experiments were performed with the organic fractions at the concentrations recovered from the process liquor. The larger molecular weight organic species $(>50 \mathrm{kDa})$, although added at low concentrations, were each seen to increase oxalate stability by between 9 $15 \%$, including the $100-300 \mathrm{kDa}$ fraction (15\%). The materials from the pregnant and spent liquor also increased oxalate stability, with the pregnant material increasing stability by $33 \%$ and the spent material by $24 \%$.

For stressed systems (Table 7), oxalate concentration in solution was shown to depend on organic dose /44/ but oxalate stability was significantly increased by the $12-25 \mathrm{kDa}, 50-100 \mathrm{kDa}$ and $>300 \mathrm{kDa}$ organic fractions with the oxalate concentration being increased by more than $16 \%$ for the largest molecular weight fraction $(>300 \mathrm{kDa})$. The smallest molecular weight fraction $(<1.2 \mathrm{kDa})$ when added at similar concentration produced no effect on the oxalate concentration. This suggests that there is some relationship between humic molecular weight and capacity to stabilise oxalate in solution. This may be because the oxalate may aggregate with the large organic macromolecules via hydrogen bonding, forming host-guest complexes in much the same way as small molecular weight Bayer humic substances may aggregate. The formation of such complexes prevents the oxalate from agglomerating into a form where it can be precipitated from solution, leading to increased concentrations of the oxalate in solution, i.e. stabilisation. 


\section{RELATIVE ACTIVITIES}

Studies with model compounds have shown that many small hydroxyorganic compounds act as poisons to the Bayer process $/ 47-52 /$. Model hydroxybenzene carboxylic acid compounds, similar in structure to those isolated in the smallest molecular weight fraction of the Bayer humic substances, were found to be effective aluminium hydroxide precipitation poisons. The present study supports the findings of the tests with model compounds, revealing that the small molecular weight compounds do affect precipitation yields, as do the larger molecular weight materials. Studies with model compounds have determined that hydroxy organic compounds produce decreases in particle size of product crystals. These findings were supported by the results obtained, as the small molecular weight material isolated from the Bayer process had very strong adverse effects on product sizing, leading to the generation of excessive amounts of fine aluminium hydroxide crystals. However such effects are only seen when there is a deficiency of sites for newly settling alumina carrying species and humic material to bind. Caustic washed seed (group A experiments) was found to minimise the decreases in yield caused by the poisoning of the precipitation of aluminium hydroxide by the Bayer organic fractions. The reductions in yield when caustic washed seed was used were much smaller than those obtained using hot water washed seed (group B experiments), even when the organic fractions were present in roughly equivalent concentrations (1.2-6 kDa, 12-25 kDa, 50-100 $\mathrm{kDa}$ and $>300 \mathrm{kDa}$ ). Caustic washed seed also minimised the changes in crystal size due to the presence of organic compounds, producing crystals of a similar size to the crystals produced with no organics present.

Hot water washed seed (Group B experiments) would already contain significant amounts of bound organics on the crystal surfaces reducing the number of potential sites for aluminate ions to precipitate from solution. Moreover the presence of additional organic compounds in solution would bind with the remaining free precipitation sites on the hot water washed seed effectively preventing further aluminium hydroxide precipitation, thus resulting in a decrease in precipitation yields. The caustic washed seed (Group A experiments) acts to decrease the inhibition caused by process organics by providing more free sites to precipitate aluminate ions. Caustic washing removes the outer crystal surfaces and bound organics from the seed crystals, thus providing additional aluminate ion precipitation sites that were previously occupied by the process organics. 


\section{CONCLUSIONS}

1. The organic matter in Bayer fractions varies considerably with molecular weight. This variation is due to the nature of the organic material that enters the process, but also depends on the conditions of processing. The type of vegetation can affect this organic matter and the rate at which it dissolves in Bayer liquors. Clear differences between Angiosperms and Gymnosperm lignins have been observed. Carbohydrates are in general unstable but some such as xylitol can have longer half-lives so they may influence the process. Carbohydrates form lactic acid and other small organic molecules which themselves can influence the process in complex ways.

2. All molecular weight fractions from $<1.2 \mathrm{kDa}$ to $>300 \mathrm{kDa}$ of Bayer organic matter affect precipitation yields, particle sizes and surface areas of product alumina; however, the effects only occur when there is competition for the number of sites at which new alumina carrying species or humic material can bind. The preparation of seed crystal is therefore very important and because of competition, effects are concentration dependent.

3. Higher molecular weight fractions $(>50 \mathrm{kDa})$ were found to be the most detrimental to the precipitation of aluminium hydroxide from Bayer process liquor decreasing product yields significantly. The $>300 \mathrm{kDa}$ fraction had the largest effect. The higher molecular weight organic fractions were also seen to have the largest impact on oxalate stability, increasing oxalate stability in synthetic Bayer liquor by up to $20 \%$. These molecules are probably largely synthesised in situ.

4. Yield, particle size and surface area of alumina from the spent liquor does not add up to the weighted sum of the respective yields, particle sizes and surface areas from the individual molecular weight fractions. Thus the humic materials must interact with each other in producing precipitation effects or interact in tandem with the surface. It is probable that initially ligand exchange of water occurs at the surface followed by a fast process where small molecular weight species occupy binding sites. These molecules are then displaced by irreversibly adsorbing large macromolecular organic species. This would suggest that all the molecular weight fractions play a role in the poisoning process, with the largest molecular weight material having a displacement role. 
5. Oxalate stabilisation in solution is promoted by higher molecular weight fractions, especially under conditions in which the system is deficient in binding sites. The highest molecular weight fraction $(>300 \mathrm{kDa})$ is the most effective. These results support a model in which humic material can capture oxalate and make it unavailable to the precipitation pool by forming host guest complexes.

\section{REFERENCES}

1. Evans AM. Ore Geology and Industrial Minerals: An Introduction. London: Blackwell Scientific Publications, 1993: 389.

2. Wefers $\mathrm{K}$ and Misra C. Oxides and Hydroxides of Aluminium. Alcoa Laboratories, Alcoa Technical Paper No. 19, 1978.

3. Solomom M, Groves DI and Jaques AL. The Geology and Origin of Australia's mineral deposits. New York: Oxford University Press, 1994: 772.

4. Hind AR, Bhargava SK and Grocott SC. The surface chemistry of Bayer process solids: a review. Colloids and Surfaces, A: Physicochemical \& Engineering Aspects, 1999; 146: 359-374

5. Grocott SC, Rosenberg SP. Soda in Alumina. Possible mechanisms for soda incorporation. Proceedings of the Second International Alumina Quality Workshop, Gladstone, Australia, 1988; 271-287.

6. Armstrong L. Bound soda incorporation during hydrate precipitation. Proceedings of the Third International Alumina Quality Workshop, Hunter Valley, Australia, 1993; 282-292.

7. Atkins P, Grocott SC. The impact of organic impurities on the production of refined alumina. Proceedings of Science, Technology and Utilisation of Humic Acids, CSIRO Division of Coal and Energy Technology, Sydney, Australia, 1988; 85-94.

8. Moolenaar RJ, Evans JC and Mc Keever LD. The structure of the aluminate ion in solutions at high $\mathrm{pH}$. Journal of Physical Chemistry, 1970; 74: 3629-3636.

9. Wilson MA, Collin PJ and Akitt JW. Composition of aluminum phosphate solutions. Evidence from Aluminium-27 and Phosphorus-31 Nuclear Magnetic Resonance spectra. Analytical Chemistry, 1989; 61: 1253-1259. 
10. Bradley SM And Hanna JV. 27Al and 23Na MAS NMR and powder X Ray diffraction studies of sodium aluminate speciation and mechanistics of aluminum hydroxide precipitation upon acid hydrolysis. Journal of the American Chemical Society, 1994; 116: 7771-7783.

11. Power G.P. and Tichbon W. Sodium Oxalate in the Bayer Process: Its origin and effects. In Proceedings of the Second International Alumina Quality Workshop, Perth Australia, 1990, p99-115.

12. Ellis AV, Wilson MA, Forster P. Degradation of Klason lignin in sodium hydroxide at $145^{\circ} \mathrm{C}$. Industrial \& Engineering Chemistry Research, 2002; 41, 6493-6502.

13. Ellis AV, Wilson MA, Kannangara GSK. Bayer Poisons: Degradation of angiosperm and gymnosperm water-soluble extracts in sodium hydroxide at $145^{\circ} \mathrm{C}$. Industrial \& Engineering Chemistry Research, 2002; 41: 2842-2852.

14. Swift RS. Macromolecular properties of soil humic substances: Fact, fiction and opinion. Soil Science; 1999; 164: 790-802.

15. Skjemstad JO, Reicosky DC, Wilts AR and Mc Gowan JA. Charcoal carbon in US agricultural soils. Soil Science Society of America Journal, 2002; 66(4):1249-1255.

16. Schmid EM, Skjemstad JO, Glaser B, Knicker H and Kogel-Knabner I. Detection of charred organic matter in soils from a Neolithic settlement in Southern Bavaria, Germany. Geoderma, 2002; 107(1-2):71-91.

17. Schmidt MWI, Skjemstad JO, Czimcizik CI, Glaser B, Prentice KM, Gelinas Y and Kuhlbusch TAJ. Comparative analysis of black carbon in soils. Global Biogeochemical Cycles, 2001; 15(1):163-167.

18. Marshall CP, Kannangara GSK, Alvarez R, Wilson MA. Characterisation of insoluble char in Weipa bauxite. Carbon, 2004; Submitted.

19. Baker AR, Greenway AM. Comparison of bauxite and Bayer liquor humic substances by ${ }^{13} \mathrm{C}$ Nuclear Magnetic Resonance Spectroscopy. Implications for the fate of humic substances in the Bayer process. Industrial \& Engineering Chemistry Research, 1988; 37: 4198-4201.

20. Given PH and Marzec A. Protons of Differing Rotational Mobility. Fuel, 1988; 67: 242.

21. Redlich PJ, Jackson WR and Larkins FP. Hydrogenation of brown coal Part 9. Physical characterisation and liquefaction potential of Australian coals. Fuel, 1985; 64: $1383-1389$. 
22. Wilson MA, Kannangara GSK and Smeulders DE. Funeral arrangements for plants: An essay in organic geochemistry. Journal and Proceedings of the Royal Society of New South Wales, 2000; 133: 7185.

23. Fetsch D, Hradilova M, Mendez EMP and Havel J. Capillary zone electrophoresis study of aggregation of humic substances. Journal of Chromatography A., 1998; 817(1-2): 313-323.

24. Ong HL and Bisque RE. Coagulation of humic colloids by metal ions. Soil Science, 1968; 106: 220-224.

25. Havel J, Fetsch D, Peoa-Mendez EM, Lubal P and Havli J. Recent developments in humic acid characterisation. Acidobasic and complexation properties, separation and reliable fingerprints by capillary electrophoresis and MALDI-TOF mass spectrometry. Proceedings of the 9th International Meeting of the International Humic Substances Society, Adelaide, Australia, 1998; 103-107.

26. Frimmel FH. Impact of light on the properties of aquatic natural organic matter. Environment International, 1998; 24: 559-571.

27. Higuchi T. Lignin structure and morphological distribution in plant cells walls. Lignin Biodegradation: Microbiology, Chemistry and Potential Applications. Boca Raton; CRC Press, 1981.

28. Criss DL, Ingram Jr LL and Schultz TP. A low-temperature internal nucleophilic aromatic substitution reaction on a $\beta-0-4$ lignin model dimer. Journal of Organic Chemistry, 1997; 62: 7885-7888.

29. Ellis AV, Kannangara GSK and Wilson MA. Chemistry of sodium lactate formation under simulated alumina refinery conditions. Industrial \& Engineering Chemistry Research, 2003; 42:3185-3189.

30. Ellis AV and Wilson MA. Carbon exchange in hot alkaline degradation of glucose. Journal of Organic Chemistry, 2002; 67: 8469-8474.

31. Smeulders DE, Wilson MA, Armstrong L. Insoluble organic compounds in the Bayer process. Industrial \& Engineering Chemistry, 2001; 40: 2243-2251.

32. Wilson MA, Ellis AV, Lee GSH, Rose HR, Lu X, Young BR. Structure of molecular weight fractions of Bayer humic substances I. Lowtemperature products. Industrial \& Engineering Chemistry Research, 1999; 38: 4663-4674.

33. Smeulders DE, Wilson MA, Patney H, Armstrong L. Structure of molecular weight fractions of Bayer humic substances II. Pyrolysis behaviour of high temperature products. Industrial \& Engineering 
Chemistry, 2000; 39: 3631-3639.

34. Lever G. Identification of organics in Bayer liquor. Light Metals, 1978, 71-83.

35. Harakuwe A, Haddad P and Jackson P, Quantitative determination of oxalate in Bayer liquor by capillary zone electrophoresis - a validative study. Journal of Chromatography, 1996; 739(1-2): 399-403.

36. Susic $M$ and Armstrong LG. High-performance liquid chromatographic determination of humic acid in sodium aluminate solution. Journal of Chromatography, 1990; 502: 443-44.

37. Whelan TJ, Wilson MA and Kanangara GSK. HPLC investigation of humics found in Bayer liquors. Proceedings of the Australian Organic Geochemistry Conference, CSIRO Marine Research Laboratories, Hobart, Australia, 2002; 77-78.

38. Jackson P. Analysis of oxalate in Bayer liquors - a comparison of ion chromatography and capillary electrophoresis. Journal of Chromatography, 1995; 693(1): 155-161.

39. Wilson MA, Ellis AV, Kannangara GSK and Whelan TJ. Transformation of organics inputs to alumina refineries. Proceedings of the $6^{\text {th }}$ International Alumina Quality Workshop, AQW Inc. Ltd., Brisdane, Australia, 2002; 67-72.

40. Whelan TJ, Kannangara GSK and Wilson MA. Increased resolution in High-Performance Liquid Chromatography spectra of high molecular weight organic components of Bayer liquors. Industrial \& Engineering Chemistry Research, 2004, in press.

41. Smeulders DE, Wilson MA and Kannangara GSK. Host-guest interactions in humic materials. Organic Geochemistry, 2001; 32: 13571371.

42. Hatcher PG, Nanny MA, Minard RD, Dible SD and Carson DM. Comparison of two thermochemolytic methods for the analysis of lignin in decomposing gymnosperm wood: The CuO oxidation method and the method of thermochemolysis with tetramethylammonium hydroxide (TMAH). Organic Geochemistry, 1995; 10: 881-888.

43. Wilson MA, Farquharson GJ, Tippett JM., Quezada RA And Armstrong L. Aluminophilicity of the humic degradation product of 5hydroxybenzene-1,3-dicarboxylic acid. Industrial and Engineering Chemistry Research, 1998; 37: 2410-2415.

44. Smeulders DE and Wilson MA. Crystal surface and humic material effects on crystallisation. Proceedings of the International Humic 
Substance Society, Boston, United States of America, 2002; 478-480

45. Smeulders DE, Wilson MA and Armstrong L. Poisoning of aluminum hydroxide precipitation by high-molecular-weight fractions of Bayer organics. Industrial \& Engineering Chemistry Research, 2001; 40: 5901-5907.

46. Mitchell $\mathrm{CH}$, Alamdari A, Wainwright MS and Raper JA. Improvement of batch precipitation of alumina trihydrate from Bayer pretreated with calcined aluminas. Proceedings of the Nineteenth Australasian Chemical Engineering Conference (Chemeca 91), Newcastle, Australia, 1991; 114-121.

47. Atkins $P$ and Grocott SC. The impact of organic impurities on the production of refined alumina. Proceedings of the Science, Technology and Utilisation of Humic Acids. CSIRO Division of Coal and Energy Technology, Sydney, Australia, 1988; 85-94.

48. Watling HR, Smith PG and Loh J. Comparative effects of model organic compounds on gibbsite crystallisation. Proceedings of the Fourth International Alumina Quality Workshop, Darwin, Australia, 1996; 553-555.

49. Smith PG, Watling HR and Crew P. The effect of model organic compounds on gibbsite crystallization from alkaline aluminate solutions: polyols. Colloids Surfaces A: Physicochemical and Engineering Aspects, 1996; 111: 119-130.

50. The PJ. The effect of glucoisosaccarinate on the Bayer precipitation of alumina trihydrate. Light Metals, 1980; 119-130.

51. Alamdari A, Raper JA and Wainwright MS. Poisoning of the precipitation of alumina trihydrate by mannitol. Light Metals, 1993; 143-149.

52. Coyne JF, Wainwright MS, Cant NW and Grocott SC. Adsorption of hydroxy organic compounds on alumina trihydrate. Light Metals, 1994; $39-45$. 